\title{
Super-diversity: elements of an emerging perspective
}

\author{
By Karel ARNAUT \\ Max Planck Institute for the Study of Religious and Ethnic Diversity
}

\begin{abstract}
This paper is an attempt to reflect upon diversity in contemporary globalising society from within the disciplinary frontier of anthropology and sociolinguistics. Like the paper of David Parkin (infra) Arnaut's is an attempt to device new frames of reference for the sociolinguistic study of super-diversity. Here Arnaut explores the potential of 'super-diversity' as a perspective or lens for looking at diversity as discourse and as social practice. The paper first looks into the notion of super-diversity, which marks a sea-change in the global design of transnationalism. Moreover, super-diversity seems to indicate that a new approach is needed to replace the model of orderly multiculturalism by taking into account the fluidities and complexities of diversity in the age of heightened mobility and digital communication. Second, this paper recognises that over the last two decades a hegemonic 'diversity' discourse has emerged in a 'post-panoptical' configuration of governmentality that manages these complex forms of diversity. The challenge of the super-diversity perspective is to relate to this hegemonic discourse while not losing track of the exciting dynamics of messy and creative commonplace diversity in every-day interaction and low-key cultural production. In order to perform this task, the paper proposes a 'critical sociolinguistics of diversity' that is presented as part of a new moment in the post-colonial history of the human and social sciences, almost half a century after the earlier decolonising moves by scholars such as Johannes Fabian and Dell Hymes.
\end{abstract}

\section{A new world of diversity?}

The anthropological point of vantage is that of $a$ world culture struggling to be born. As a scientist, the anthropologist both represents its embryonic possibilities and works to create it. If that culture fails, so will anthropology (Wolf 1964: 96 [my emphasis] quoted in Hymes 1972: 19 and cited again on p. 30).

The above is a key passage from Hymes's Reinventing Anthropology (1972), an edited volume that fostered a crisis in anthropology by questioning the discipline's societal relevance and scientific legitimacy, while raising important ethical issues related to its changing position in a new, postcolonial world. Hymes's programmatic introduction tried to lay out the basis of anthropology's reinvention within a long (Western) tradition of dealing with - describing, explaining, and managing/governing - diversity vis-à-vis universal human nature and culture (Hymes 1972: 22). Two facets of this undertaking are of particular interest: the idea of universality-in-progress, and that of infinite diversity within a closed system.

When Hymes (1972: 34) states that it was the task of anthropology 'to establish the study of the cultural as a universal and personal dimension of human efforts toward the future', he situates the future explicitly in 'a world society' and in the on-going human quest for commonality and reciprocity through communication (idem: 35). These ideas have been rearticulated more recently by Bruno Latour as vital elements of his theory of 'compositionism'. The universality which the humanities are searching for, Latour (2010: 474) argues, is not yet 'there', 'waiting to be unveiled and discovered'. Bringing in the element of diversity, he specifies that this common world in the making will have to be built 'from utterly heterogeneous parts that will never make a whole, but at best a fragile, revisable, and diverse composite material' (2010: 474). Like 
Hymes, Latour situates the general trajectory of universality in a concrete global history of uncertain unification.

For Hymes, the post-colonial world heralds the end of diversity as we know it. Diversity, he argues, should no longer be located in an ongoing trend of diversification - through dispersion and fragmentation in an ever expanding world - but in processes of 'reintegration within complex units' (Hymes 1972: 32-33; emphasis in the original). The finite world that is evoked here resembles the one Paul Valery (1931: 11) saw as following on 'the era of free expansion' (see Birkett 2006) and which, for Wolf, radically rekeys our way of dealing with human diversity. 'For the first time in human history,' Wolf claims, 'we have transcended the inherited divisions of the human phenomenon into segments of time and segments of space' (Wolf 1964: 95). Instantly gauging the theoretical implications of this global repartitioning and the (avant la lettre) compression of space-time, Wolf predicts that 'no one stationary perspective will any longer exhaust the possibilities of man' (idem). Finally, he casts the newly emergent analytical gaze in terms of multiplicity and mobility:

We have left behind, once and for all, the paleotechnic age of the grounded observer who can draw only one line of sight between the object and himself. We have entered the physical and the intellectual space age, and we are now in a position to circumnavigate man, to take our readings from any point in both space and time (idem).

For Wolf this decentring of dominant segmentations and static 'points of view' requires anthropologists to discard simplicity, predictability, and stasis, and to confront the 'variability and complexity of human life' (1964: 96-97). Moreover, agility and suppleness enable anthropologists to take sides - and throw in their fate - with their interlocutors, and lay the basis for a more democratic and emancipatory science of the human life experience based on mutuality and exchange. In that respect, Wolf and, more explicitly, Hymes (1972: 39, 53, 57; 1975: 869) display a Bakhtinian susceptibility for the liberatory potential of the humanities (see Hirschkop 1986; Blommaert 2009).
Around the same time of Hymes's and Wolf's post-colonial anthropology, members of the Italian so-called autonomist 'movement of 1977' started theorising the post-Fordist condition of mass diversity ('the multitude') and its reproduction in a global environment (Virno and Hardt 1996). Among them, Antonio Negri (2008) identifies the human creative potential/energy by referring to Spinoza's notion of potenza (Ruddick 2010). While globalisation signifies the end of the world having 'an outside', Negri contends, potenza realises itself in the 'recomposition of the sensible', the 'poetic reconstruction of life from the inside' in a world that is finite and yet limitless (Negri 2008: 68-69, 239). This potenza, Negri (2008: 7) argues, will increasingly be realised through what he and others call immaterial labour, in which communication and the creation of 'linguistic, communicational, and affective networks are key elements'. Negri thus shares with Virno the idea that at the present stage of globalisation - whether you call it 'empire' (Hardt and Negri 2000) or 'post-Fordism' (Virno 2004), or as we shall see presently 'postmodernism' - the means of production consist to an increasing extent of communicative techniques, procedures and competencies (Virno 2004: 61).

From the early 1990s onwards, post-modernist theorists have equally tried to come to terms with human agency and creativity in a 'finite yet limitless' world. In Zygmunt Bauman's seminal text, this world is epitomised by the 'habitat' that 'offers the agency the sum-total of resources for all possible action as well as the field inside which the action-orienting and action-oriented relevancies may be plotted, the habitat is the territory inside which both freedom and dependency of the agency are constituted ...' (Bauman 1991: 36). Subsequently, Bauman characterises this new habitat as complex and highly unpredictable, not in the least because of its polycentric character, there being 'no goal setting agency with overall managing and coordinating capacities or ambitions'. Within this habitat he situates the processes of self-assembly (close to Virno's notion of 'individuation') or contingent, inconclusive self-constitution and stresses how much 
they depend on the availability and accessibility of resources ( $=$ 'tokens for self-assembly') (Bauman 1991: 36-40). In a later text, Bauman (1996: 18) summarises the finite nature yet the inexhaustible possibilities of these processes by saying, 'the catchword of modernity was creation; the catchword of postmodernity is recycling.'

Finally, Bauman (1991: 46) conceives of the researcher 'as participant [...] of this never ending, self-reflexive process of reinterpretation [...]. In practice, [...] a clarifier of interpretative rules and facilitator of communication; this will amount to the replacement of the dream of the legislator with the practice of an interpreter.' Perhaps because of Bauman's focus on issues of communication and semiotisation, Rampton (2006: 12-16) engages with several of Bauman's key points in order to start mapping out his own sociolinguistics of late modernity. As I hope will become clear, the present paper shares some of these aspirations.

This paper is an attempt to reflect upon diversity in contemporary globalising society from the disciplinary frontier of anthropology and sociolinguistics embodied in the section above by scholars such as Hymes, Wolf, and Bakhtin. This reflection is meant to generate elements for elaborating 'super-diversity'. While this notion has the ambition of summarising the new guise of diversity in this age of complex transnationalism, it has the potential, I argue, of becoming a perspective or lens with which to look at diversity as social practice, of course, but also as discourse. This I wish to do in three steps.

\section{Overview}

In the first section I briefly look into the notion of super-diversity. The latter wants to mark a new historical condition of transnationalism stemming from the fact that the global flows of people have been undergoing profound quantitative and qualitative changes since the late 1980's. Apart from marking a sea-change in the global design of transnationalism, super-diversity also indicates that a new approach is needed to replace the inadequate model of multiculturalism by taking into account the fluidity and intricacies of the new diversity in the age of heightened mobility and transnational communication. In the second, I explore the ways in which a hegemonic diversity discourse has emerged over the last two decades. This paper explores the breadth and depth of this discourse and situates it in a configuration of governmentality that it identifies as post-panoptical. This leads to the question of how super-diversity can relate to this hegemonic diversity discourse while not losing track of the exciting dynamics of commonplace diversity in every-day interaction and low-key cultural production.

In the third section, I argue for the concept of super-diversity to foster a 'critical sociolinguistics of diversity' which pursues (a) a sustained critical analysis of the emergent hegemonic diversity discourses as well as 'older', residual but still competing discourses of multiculturalism or multilingualism, while (b) addressing the way diversity in combination with transnationality is being shaped and reworked in language use and communicative practices. The latter's study, I argue, demands a radical ethnographic openness in order to deal with the unpredictability as well as the transient and emergent nature of these practices, networks, and spaces. This combination of ethnographic openness and a keen awareness of hegemonic dynamics situates the critical sociolinguistics of diversity as part of a new moment in the post-colonial history of the human and social sciences, almost half a century after the earlier decolonising moves by the likes of Johannes Fabian and Dell Hymes.

\section{First step: gauging super-diversity's theoretical Umwelt}

The concept of super-diversity marks the new condition of transnationalism since the late 1980 s and arguably accounts for the 'reintegration within complex units' to which it gave rise. Already in its earliest definitions, super-diversity (Vertovec 2006) linked major geopolitical changes, notably the end of the Cold War, with the rise of new migration flows and the diversification of migration patterns and practices worldwide. This diversification applies not only to the range of migrant-sending and migrant-receiving countries, but also to the socio-economic, cultural, religious, and linguistic profiles of the migrants as well as 
to their civil status and their migration trajectories. In contrast, the pre-1990 (and mainly postWWII) labour or elite migrations to Europe were conceived as transparent and orderly because the migrants stemmed from a limited number of countries - from Mediterranean 'labour reservoirs' or former colonies in Africa and Asia and had rather similar socio-economic, cultural, religious, or linguistic backgrounds (Blommaert 2011; Parkin and Arnaut 2012). The diversity following these post-war migrations was conceived and indeed governed and managed as a 'multiculturalist' constellation of regimented ethnocultural segments (Hall 2000: 209). Although it had always been contested, by the 1990s this system of governance, according to Hall, was close to its ultimate demise, playing as it was against 'the reconfiguration of social forces and relations across the globe' (ibid.: 212).

Post-1990s transnationalism presented a different picture altogether and is, in the words of Vertovec (2007b: 1024), 'a dynamic interplay of variables among an increased number of new, small and scattered, multiple origin, transnationally connected, socio-economically differentiated and legally stratified immigrants who have arrived over the last decade.' Concurrently, super-diversity scorns the false transparency and neatness of 'multiculturalism' - a concept or set of policies whose pluralism Vertovec (2010: 90) aptly characterises as legitimising 'a retreat into culturally and physically separate minority communities.'

In its sustained critique of multiculturalism, one may sense super-diversity's aspiration to pass from being merely a 'summary term' to becoming an emergent approach or a perspective (Fanshawe and Sriskandarajah 2010; Vertovec 2010; Blommaert and Rampton 2011). An important step in this direction consists in inventorying the many variables of present-day transnationality in order to grasp 'their scale, historical and policy-produced multiple configuration and mutual conditioning' (Vertovec 2007b: 1026). This could form the basis of 'calculi' or topographies of diversity variables and their intersections. Here it becomes obvious how 'simultaneity' is potentially an important element of the emergent perspective of super-diversity. Apart from being constitutive of super-diversity, simultaneity also catches the imagination of the human and social sciences, and thus serves to embed the former in the latter - as I will presently try to do.

The notion of simultaneity is built into that of super-diversity by Vertovec's observations concerning multiple belongings in diasporic configurations (Vertovec 2007a: 34) or by referring to other authors who observed that people 'can engage in multiple transnational processes at the same time', hence the need to 'explore how transnational practices and processes in different domains relate to and inform one' (Levitt and Glick Schiller 2004: 1028). Sociolinguists have also been engaging with the notion of simultaneity, for instance, in connection with multi-membership in different communities of practice (Barton and Tusting 2006: 97; and see Wenger 2000), the co-presence of a multiplicity of communicative channels, from face-to-face to mass media (Jacquemet 2005: 217) or the copresence of different languages or codes in the same word or segment (Woolard 1998) as well as in code-switching which, according to Rampton (1995: 278) functions as a kind of 'double vision', an 'interaction between co-present thoughts' or a 'transaction between contexts'. The existing toolkit of sociolinguistics appears rather wellequipped to deal with phenomena of space-time compression (Blommaert 2010; Blommaert and Rampton 2011; Coupland 2010; Vigouroux 2008).

The transidiomatic practices and communicative recombinations which Jacquemet (2005), for instance, maps out across genres, media, and transnational public spaces, acutely indicate how people operate in multiple layers of identification (Alim 2009: 104). Simultaneity, in other words, helps us to look at migratory or diasporic spaces as spatialisations of time, that is, as successive palimpsests of multiple trajectories (see Massey 2001: 259). That is where the popular notion of scale often comes in, consciously or not, conceived as part of a production process of 'gestalts of scale' (or glocal scalar fixes) in states or cities by unequal groups (see e.g. Swyngedouw 1997). Two recent cases demonstrate how a sca- 
lar approach to cities elicits urban fragmentation even at a very micro-level. Blommaert (2012) and Van Dijk (2011) both look into very similar diasporic hot spots - globalisation gateways in train station neighbourhoods in Antwerp and The Hague, respectively. Against 'methodological urbanism' Van Dijk (2011: 121) stresses that what goes for neighbourhoods does not necessarily apply to cities as a whole, given the fragmented and unequally transnationalised nature of the global city. In his linguistic landscaping research Blommaert (2012: 124) goes so far as to observe "layered simultaneity" both in single signs as repositories and "nexuses" of complex and "synchronized" histories, and in the neighborhood at large.'

Ultimately, the analysis of complex simultaneity also directs attention to the spatiality and, perhaps paradoxically, the diachronicity of transnational processes in virtual environments. Here, the sheer speed and geographical reach of Internet communication may compress but does not eliminate time and space. The speed at which resources on the Internet circulate, are reworked or resemiotised and rechanneled, demands a conceptualisation in terms of simultaneity as layered traces of short-term communicative actions (Leppänen and Peuronen 2012). In studies of political protest or social movements, the concept of 'scale' has been used to map out the transfer of resources across scales, that is, across publics of different reach both transversally (widespread mobilisation) and hierarchically (more high-up, power-laden zones) (Howitt 1993; Arnaut 2005; see Marston 2000: 222). Following a decade or so of intense popularity, the notion of scale is currently under heavy attack, more particularly its conceptualisation as (a) a territorial container and (b) a geographical hierarchy of everyday power relations. In their critiques Moore (2008) and Marston, Jones and Woodward (2005) argue against scales as pre-given, horizontally bounded, and vertically or hierarchically ordered so as to open space for the dynamics of rescaling in social and discursive practices of activism, networking, neighbourhood building, etc. I will come back to this later, when situating this in a 'critical sociolinguistics of diversity'.
Whether we measure this in terms of scales or not, simultaneity reaches 'down' to the level of the individual, or rather, the 'dividual' and 'upwards' to that of the globe. Starting with the former, it is noteworthy how, apart from postmodernism, post-colonial critiques of identity and diversity (indeed colonial multiculturalism) have also embraced models of identification and multiplex subjectivities. Commenting on postmodern models of 'dividuality', Bennett (1999: 605) claims they see 'persona' of the same individual move "between a succession of "site-specific" gatherings and engage in "multiple identifications" while producing a self which can no longer be simplistically theorized as unified.' From a post-colonial perspective, Englund argues that:

multiplicity is not so much a feature of a postcolony that comprises several distinct 'cultures' or 'communities' than of post-colonial subjectivity that accommodates multiple identities within a single subject. Complex relations cross cut each other as persons belong to this or that church, swear allegiance to one or another ethnic group, belong to a secret society and a political party, are business partners as well as civil servants, and so on (Englund 2004: 14).

In his writings on the post-colony Mbembe elaborates a persona-like model of the post-colonial subject and its tactics of 'impersonation' in diverse settings (Mbembe 1992; Mbembe and Roitman 1997). In the context of post-Apartheid South Africa he extends this claim to 'the world' as 'a multiplicity of worlds' whose 'unity is the mutual sharing and exposition of all its worlds - within this world' (Mbembe and Nuttall 2004: 351).

In conclusion, the contrast between multiculturalism and super-diversity is perhaps best theorised by Deleuze (with reference to Foucault) in the distinction between disciplinary and control societies, and more specifically between moulds and modulations. For Deleuze (1992), the postmodern crisis is the crisis of plurality of neat divisions which he calls enclosures or moulds. Such moulds can best be understood as compartments in Bentham's panopticon (as remodelled by Foucault) in which a subject's conduct is shaped, cast or moulded. In contrast, in so-called 
post-panoptical systems, subjects engage in controls as modulations: they are constantly open ('on') for calibrations or alignments in variable directions (see Fraser 2003; and Bauman 2000: 11 for post-panopticon). Cheney-Lippold (2011) shows how this control society manifests itself in a broad range of surveillance schemes (ranging from CCTV to GPS-traceable mobile phones), checks and feedbacks (administrative or commercial), mostly through ICT and often based on government or corporate databases:

And modulation [creates] not individuals but endlessly sub-dividable 'dividuals'. These dividuals [...] the recipients through which power flows as subjectivity takes a deconstructed dive into the digital era. [...] dividuals can be seen as those data that are aggregated to form unified subjects, of connecting dividual parts through arbitrary closures at the moment of the compilation of a computer program or at the result of a database query (Cheney-Lippold 2011: 169; my emphasis).

It is far beyond the scope of this paper to expand on modulation theory and on profiling as subjectification. It suffices to realise that once one starts exploring the theoretical habitat in which super-diversity is both intelligible and relevant, one realises that individuality and diversity are key-zones of broader systems for ordering and regulating societies at different levels (simultaneously). In other words, when dealing with models of global and local diversity and how they are imagined as evolving over time, it is difficult to steer clear of 'discourse' and 'governmentality'. One of the critical issues identified so far, by looking at super-diversity through the lens of simultaneity and, hence, scalarity, is the degree of openness, flexibility and thus novelty that 'reintegration within complex units' affords. What seems to return continuously is the seemingly paradoxical combination which Hymes and Wolf foregrounded by characterising postcolonial late modernity as unfolding in a 'finite and yet limitless' universe. Stated otherwise, do we solve this paradox by directing our attention to the finite resources and categories with which one starts off (but when?) or to the limitless outcomes of their interplay? This indeed seems to be at stake when looking at diversity in a governmentality configuration, which, for want of a better term, I label post-panoptical.

\section{Second step: delving into diversity discourses -} 'diversity' and 'counter-diversity'

In a recent paper, Steven Vertovec (Vertovec 2012) explores the swift rise of what he calls 'diversity' (in quotation marks) - 'discourses about diversity' - the worldwide upsurge of which is resulting in the ubiquity of diversity in the 'policies, programmes, campaigns and strategies' of private corporations, public institutions, civil society organisations, etc. Vertovec's pungent analysis reveals not only (a) the breadth of 'differences' that comprise 'diversity', but also (b) the extent to which diversity discourses, policies and practices penetrate the lives of people and groups of people.

(a) Over the last decade, the number of diversity categories that are taken into account has soared and now ranges from the classics (such as race, gender, ethnicity, and social class) to less obvious and far more open-ended ones such as opinions and beliefs, backgrounds and experiences. Most revealing in this respect are the expectations of Kenneth Prewitt, former director of the US Census Bureau, who sees two possible outcomes of the rising complexity and uncertainty of diversity profiling. For Prewitt, the unlikely prospect is that measurements of difference will become ever more fine-grained, while the more likely one is a melt-down of the measurement system as we know it (Vertovec 2012: 289-290).

(b) When presenting what he calls the different facets of 'diversity', Vertovec (2012: 296-301) demonstrates compellingly how the latter permeates the everyday political, economic, affective, and civil lives of people as it gains prominence in mechanisms of redistribution and recognition, in systems of representation and organisation as much as in calibrating the provision of public services and in codirecting companies' production and sales strategies.

Taking these two observations together, we may seem to be heading towards a situation in which 
'diversity' gains immense presence and authority in management and governance worldwide, but at the same time pays the price of its success by losing transparency and calculability. One way of resolving this conundrum is arguing that the infinitesimal finesse of diversity could drive a potently flexible system of expression and control. If that is the case, 'diversity' may be productively approached as a(n emergent) discourse in the Foucaultian sense of the word: as an attractor of individual and collective ideas, words and actions, scattered in corporate policies and civil society activism, scaffolding the modernity of nation-states and the future of cities, driving individual consumer patterns and collective claims for recognition and redistribution. Attributing to 'diversity' the status of a (dominant) discourse is not an end in itself and has certain heuristic advantages. First of all, one realises that 'diversity' is more than a collection of ideas and (action) models concerning all sorts of differences, rather it is a widely spread, globally recognisable and legitimate discursive space in which people from very unequal positions imagine, formulate, and work on their individual and collective identities. However, diversity discourses are essentially local - very much in the same sense that 'global English' is local (Pennycook 2007) - and cannot be safely taken as more or less close offshoots of more global versions. For each locality the topography of its diversity discourses, constitutive of its very local 'diversity', must be mapped out. In all, such a conceptualisation of 'diversity' challenges us to consider to what an extent 'superdiversity' is academia's contribution to 'diversity' in mapping out the relevant differences and their intersections. Or could 'super-diversity' possess more of a critical potential?

The first steps which this section proposes for exploring such critical potential are: (a) looking (very briefly) into a comparable case of dominant discourse, namely that of 'development', a now largely residual discourse which widely dominated understandings of the 'global south' during the second half of the $20^{\text {th }}$ century; and (b) trying to situate 'diversity' in a broader frame of reference, which, for want of a better term, I call the post-panopticon, arguably an emerging discourse which tries to grasp the complexity and multiplicity of communication and interaction in such exemplarily translocal spaces such as cities and cyberspaces.

Development. One notorious instance of anthropologists spotting a dominant discourse while trying to estimate its global magnitude and pervasiveness dates back to the 1990s and concerned 'development', 'that twentieth-century global project' according to one of its main critics, James Ferguson (1997), who elsewhere characterised it as 'a dominant problematic' or an 'interpretive grid' for dealing with the nonindustrialised non-Western countries (Ferguson 1994: xiii). Like 'diversity', 'development' can be taken as a discourse for positioning or mapping 'otherness'. With reference to the previous point about expansion and integration, 'development' fits an expansive universe, with others 'out there' progressing in all sorts of ways, rapidly or slowly, while 'diversity' rather suits an integrating pluriverse in which so many social, cultural, linguistic, etc. trajectories intersect. Furthermore, the comparison of 'diversity' and 'development' raises issues which cannot be dealt with in any detail here, but which help us elicit some of 'diversity's' main features. These issues concern normativity, hegemony and efficacy.

As far as normativity is concerned, 'development' presumes a sense of direction (a telos) while 'diversity' appears less driven than floating, more 'bricolage' than 'engineering'. However, that does not preclude 'diversity' from featuring in global hegemonies. With regard to hegemony, a question once formulated by Escobar and Ferguson vis-à-vis 'development' can be asked of 'diversity': Is 'diversity' not another attempt by the centre, the site of privilege named 'the West', to structure/regiment 'the rest', its others, through the diacritics of their differences or 'fragmented otherness'? After the disorientation and fragmentation (or 'decomposition') of modernity - say 'development' -, according to Ferguson (2005), these 'others' have come to realise that when it comes to creating new life chances, changing the dynamics ('developing') of their places (the global south) is less effectual 
than changing places (migrating) altogether. Correspondingly, while 'development' was essentially geared towards managing the other from a distance - or even keeping the other at a distance, 'diversity' rather deals with the (immigrated) other within.

Finally, the issue of efficacy - of whether these discourses are able to bring about real changes - seems pertinent. In the case of 'development', Ferguson argued that development projects do not need to be successful in attaining their goals, what matters are the windows of opportunity they create for (powerful) stakeholders, such as local or national authorities, transnational agencies, etc., who can pursue political goals under the veil of socio-economic development - hence Ferguson's labelling of 'development' as 'the anti-politics machine'. A similar question is asked by Vertovec (2012: 304) with regard to 'diversity': how much of 'diversity' is about reducing discrimination of 'others'? Otherwise, perhaps 'diversity' is more about obtaining access to people's practices and strategies of identification rather than about working towards the enfranchisement of those who are discriminated or marginalised on the basis of one or the other aspect of their identity, bodily dispositions, or lifestyle. In other words: was diversity as a potential instrument of empowerment from below turned into a precision tool of manipulating difference 'from above'?

Rather than pursuing the above similarities and parallelisms between 'development' and 'diversity' in their own right, the latter could learn one important lesson from the rather merciless scholarly controversy surrounding Ferguson and Escobar's 'discourse' thesis: that a productive way of investigating the workings of 'development' discourses is not to assume their existence and speculate on their ubiquity and influence, but to observe and analyse how they play out in manifold concrete development encounters and interactions (Grillo 1997; Olivier de Sardan 2005). This is precisely what I will argue in favour of when proposing a critical sociolinguistics of diversity. The latter takes concrete encounters or events as sites where diversity is being articulated, experienced, and made sense of with com- municative and discursive resources that circulate locally or more broadly, reluctantly or more powerfully. Without blindly reifying the more powerful and global resources, these characteristics can be taken to indicate their hegemonic character. The struggle of this paper is, as we will see, a Bakhtinian one in that a focus on practices and emerging structures/normativities does not preclude a topography of (relative) inequality, of 'high' and 'low'.

Post-panopticon. Before pursuing this, it is essential to come to grips with how discourses like 'diversity' work in broader configurations of global governmentality. The prevalent configuration is the one I choose to qualify, after Bauman (2000), as 'post-panoptical'. Post-panopticon is derived from Foucault's panopticon (1975) as a scopic technology and a centralist, static regime of power/knowledge of which the interactive deficit is indicated by the contrast between an all-seeing, authoritative viewer and a defenselessly exposed and 'blind' target as well as the basic condition for unequal transparency and accessibility. Contrarily, the post-panopticon is interactive and decentralist, even messy and opaque. The term 'post-panopticon' has been applied to, and seeks to elicit parallels between, such diverse domains as governance, knowledge systems, and media use (Kaplan 1995; Mathiesen 1997; Bauman 2000; Weibel 2002; Haggerty 2006; Maguire 2009; Mirzoeff 2011). Four characteristics stand out: transnationality, multidirectionality, heteronormativity/polycentricity, and the intertwining of visibility and mobility.

Above anything else, the post-panopticon needs to be situated in the 'new geographies of governmentality' (Gupta and Ferguson 1992), which are exemplarily those of cities (Appadurai 2001: 25) and cyberspaces (Mirzoeff 2011). In contrast to the top-down, unilateral interactions of the panopticon, those of the post-panopticon are multidirectional, muddled (Valentine 2008), and transversal (Simone 2005). One of the most telling instances of such multidirectionality is what Nielsen (2011) described as 'inverse governmentality', whereby in casu marginalised people living on the fringes of the city in sub- 
Saharan Africa themselves shape 'the governing powers which condition their everyday interactions' 'by drafting and implementing (illicit) urban plans' (Nielsen 2011: 353). These interventions closely resemble those described by Appadurai among homeless organisations in Mumbai that engage in self-enumeration and self-surveying as strategies of 'auto governmentality' or 'counter-governmentality' (Appadurai 2001: 34). Simone also marks the importance of similar 'planning from below' (Simone 2003: 231), but points out that urban publics in such interventions work towards transcending arrangements ('forms of being together or of being connected') rather than 'coming together to consensually decide the common rules of participation' (Simone 2010: 288). The heteronormativity of such counter-governmentality is perhaps best illustrated by the story of the Internet: a military panoptical technology that was appropriated, transformed and expanded into a composite global infrastructure of communication, socialisation and learning. Lastly, in media studies the post-panoptical relates to the omnipresence of digital technology and mobile communication, and looks at how deep mediatisation is changing the classic 'panoptical' relations (Koskela 2004; Andrejevic 2006). Two principal shifts can be argued to make up the post-panopticon: (a) the shift away from neatly hierarchised media transfers between senders and receivers towards the capillary dissemination and emerging ubiquity of media production and consumption (Hand and Sandywell 2002); and (b) the shift from static to hyper-mobile media use (Corner 1997).

The first shift consists in the radical democratisation of the uses of media. Whitaker's (1999) 'participatory panopticon' and Guattari's 'postmedia' (1990) combine inspection 'from above' with 'self-surveillance' from below. Video and surveillance cameras (CCTV), the Internet, webcams, smart phones, etc., produce still as well as moving images, and circulate them at great speed over large distances. For Boyne (2000: $301)$ 'the machinery of surveillance is now always potentially in the service of the crowd as much as the executive.' This horizontality and reciprocity of the post-panopticon stands in stark contrast to the hierarchical verticality of the panopticon as described by Foucault (1975: 256).

The hyper-mobile aspect of the post-panopticon relates to the fact that media devices become ever more compact and mobile, enabling mediausers to increasingly encroach on each other's personal/private spaces (Fetveit 1999: 791). This not only applies to individual smartphones or to web communication, but also to the professional media such as television formats and genres which make abundant use of 'scopic mobility' (Corner 1997: 15). One of the eminent exponents of this development is the multifarious genre of reality television. Dovey (2000: 26) calls this 'first person media' because it relies on the 'constant iteration of "raw" intimate human experience.' The deep sharing that comes with the relative media mobility stands in sharp contrast to the encapsulation or compartmentalisation which (together with verticality), Foucault (1975: 256) identified as one of the two basic characteristics of the panopticon. In terms proposed recently by Mirzoeff (2011), post-panoptic visuality is the key element of the present-day 'global counterinsurgency' predicament which combines extreme forms of (often digital) visualisation (e.g. computer warfare) with new strategies of optical invisibility through chaotic, informal or underthe-radar operations and counter-surveillance from below - what Cascio (2005) calls 'sousveillance'.

The type of diversity that fits the post-panopticon sketched above is one that is steeped in contingent processes of articulation and results in fluid and unpredictable 'metro-identities'. For Stuart Hall, identification is the changing outcome of a 'relation of subject to discursive formations' conceived 'as an articulation' in the sense worked out by Laclau, whereby 'all articulations are properly relations of "no necessary correspondence" ', i.e. founded on that contingency which 'reactivates the historical' (cited in Hall 1996b: 14). In the context of intensified transnationalism in urban and cyber contexts, Maher coined the term 'metro', which he first used in combination with ethnicity (Maher 2005) - in the sense of Hall's new ethnicities - and later also with language. In tune with what I described 
above as the post-panoptical, 'metro' for Maher (2010: 577) 'points to phenomena that travel below the radar of bordered perceptions of ethnicity and language; more underground (metro) than overground.' Metroethnicity and metrolinguistic styles are typically situated in the fast and fluid spaces of metropolitan urbanity and the Internet. Finally, by virtue of their inherent capriciousness and ephemeral nature, 'metro' phenomena retain an oppositional potential: they resist 'reified essentialist ethnic, religious, and cultural identities....' (Maher 2010: 577).

But, even if transient metro-identities are bound to elude the unwieldy apparatus of multiculturalism and multilingualism, they may be recuperated by the more supple and pervasive 'diversity', particularly in its consumerist dimension. The mobility and flexibility of identification in what Bauman (2000: 90) calls a 'shopping around' type of life, are not so much 'vehicles of emancipation' as 'instruments of the redistribution of freedom'. This of course is a thorny matter and it is not quite clear whether Bauman is being cynical. The way I understand it is that 'diversity' gets under people's skin in often very sophisticated ways; it gets to people in whatever way they identify or not, seek to align with or distance themselves from certain facets of identity, patterns of consumption, lifestyles, etc. In sum, 'diversity' inscribes choices as ontological facets of identity, grounds them as items of one's being that require to be accommodated, looked after, catered for, or taken care of. That opens myriad ways of consumption and commodification - a predicament Bauman (2000: 90) aptly summarises as 'divided we shop'. Here, 'diversity' appears as a post-panoptical system of control/ management/subjectification and self-realisation. Such, of course, does not preclude the fact that 'diversity' or the identifications to which it gives rise are resisted or reworked in metro-identities of some kind or other.

Although all this is very speculative and approximate, it is important to see the immense possibilities 'diversity' or 'counter-diversity' offer for self-realisation by individuals and for entrepreneurs, authorities, and markets to deliver the goods and services and to assist in that multiplex self-realisation. A critical sociolinguistics of diversity is called upon to address this.

\section{Third and last step: towards a critical sociolinguistics of diversity}

The critical sociolinguistics of diversity, whose contours are explored in this section, is an attempt to answer two related questions concerning super-diversity as an emerging perspective: (a) why does sociolinguistics need superdiversity, or what can super-diversity offer present-day sociolinguistics? ${ }^{1}$; and (b) can the notion of super-diversity be situated in the debate on post-coloniality, or could super-diversity be a second important step in the decolonisation of the human sciences?

In the opening section of this paper we looked at how in the 1960s and 1970s a significant attempt was made from within the frontier zone of anthropology and linguistics to further the decolonisation of the human sciences by reconceptualising cultural production in terms of complexity and mobility. Therefore, the question now is double: if super-diversity could contribute to anthropology and sociolinguistics, would this contribution add another impulse to their decolonisation trajectory? Before dealing with the former issue of contribution, let us first look at how super-diversity could fit into the story of decolonisation. One such recent and relevant story is the one Mbembe (2010) told in connection with Africa and the way its decolonisation confronts present-day complexity and mobility.

The first massive, often violent move of decolonisation consisted in breaking down the panoptical system of differentiating and territorialising racial identities, ethnic characters and (tribal) cultural-linguistic units (Chauveau and Dozon 1987; Mamdani 1996; Makoni and Pennycook 2007). For Mbembe (2010), this older moment of decolonisation and transgression (of the 1960s) has been supplemented by a second moment of intensified migration and the formation of new diasporas in the course of the 1990s. This dispersion and circulation is resulting in a multipolar

1 This question was asked to me by Lian Madsen in August 2012. 
Africa and is made up of processes of 'metissage and vernacularization' in an overall 'aesthetics of interlacement' which Mbembe calls afropolitanism (ibid.: 228-231). It does not require much of an argument to equate the second moment in the post-colonial worlding of Africa with the moment of super-diversity in Europe.

The sociolinguistic counterpart of this operation is what Makoni and Pennycook (2007) call disinventing and reconstituting languages both in the ex-metropoles and their former colonies. This operation, again, corresponds in its most basic aspects with what Blommaert and Rampton (2011) put forward as contemporary sociolinguistics' potential contribution to the study of super-diversity. In a nutshell, Makoni and Pennycook (2007) denounce multilingualism, which, in the case of (colonial) Africa, was an 'instrument of exploitation'. Programmatically they do not opt merely for disinventing and exceptionalising languages as separate and enumerable categories, but also for a radical creolistics, which posits the normality of transidiomatic practices and creoles against all claims to know, count, name and define languages. These suggestions indeed come very close to what many others have suggested in the way of heteroglossic blending, such as, Jørgensen's (et al.) polylingual languaging, Rampton's crossing and styling, Creese and Blackledge's translanguaging, etc. (see Blommaert and Rampton 2011:7 for an overview). The counterpart to Makoni and Pennycook's exceptionalising move consists in looking for emerging structures and normativity in this pool of fluidity, creativity and communicative agency - 'something identifiable, nameable, [and] determinate' (Rampton 2013) or 'patterns offering perceptions of similarity and stability' such as registers (Blommaert 2007: 117). These affinities between the explicitly 'decolonising' sociolinguistics of Makoni and Pennycook and the main ingredients of what Blommaert (2010) calls a 'critical sociolinguistics of globalization', largely confirm what sociolinguistics can contribute to the study of super-diversity. However, these affinities also carry strong indications of the reverse type of dependency relation: why sociolinguistics needs super-diversity as an emerging perspective. The very provisional answer to this question is a three-step trajectory in which Fabian and Bakhtin are our main guides.

A critical sociolinguistics of diversity (hereafter CSD), it seems, must set off from super-diversity's transgressive moment, which consists of discarding the false certainties of multiculturalism and its endorsement of established differences and hierarchies. This is sociolinguistics' entry into the post-panopticon of unregimented, messy, transversal interactions among actors who enjoy the relative openness of performing 'dividuality' in metrolingualism, in styling and crossing, in activating certain repertoires, in engaging in certain alignments, etc. This is nicely summarised by Fabian albeit in the idiom of theatre:

Moral and political multiculturalism are the privilege of the powerful and the protected. Courage, imagination, and practice are needed to meet otherness in its everyday theatrical forms of selfpresentation with all its tricks and props, postures and poses, masks and costumes, white-face and blackface (Fabian 1999: 30).

The second step consists in CSD embracing the radical unpredictability that comes with the melt-down of the diversity measurement system which super-diversity has provoked. Directly linked to super-diversity's special focus on transnationalism, CSD engages with foreignness as never before (Riley 2007: 162) and can only overcome its lack of familiarity through painstaking interaction, which Fabian (1979) described some time ago:

As it seems now, sociolinguistics is at odds with the 'changing', processual, creative and emergent characteristics of communication because its rules only catch established features and, perhaps, some variation within established features. It has, therefore, considerable difficulties with communicative exchanges between speakers who are not members of the same community, who do not share systems of rules, at least not fully, and whose interaction is such that in all probability they will never share all the rules. This is the case of the foreigner or stranger who settles in another society and whom sociolinguists, tellingly enough, tend to view as an irritating deviant, not as a person who creatively transcends confines of socially sanctioned rules of communication (Fabian 1979: 18). 
There is little doubt that contemporary sociolinguistics is fairly well equipped both theoretically and methodologically to deal with the challenges of the 'the unexpected', not in the least because the latter is increasingly thematised as such (Blommaert 2012; Pennycook 2012). Key to this unexpectedness is that actors, speakers and writers, participants in communication are endowed with enough agency to transcend the established correlations between the variables of their speech and certain predetermined social categories. The third wave of variation studies, Eckert (2012: 97-98) argues, mainly referring to Silverstein's 'indexical mutability' and Agha's 'enregisterment', has reversed the relation between language and society: speakers have become 'stylistic agents, tailoring linguistic styles in ongoing and lifelong projects of self-construction and differentiation' (see also Gumperz and Cook-Gumperz 2008: 540). In a similar vein, for Pennycook (2012: 124), genres, discourses and style need to be understood 'as practices that form the texts, knowledge and identity of which they speak. This position then makes it possible to see language practices as part of the formation of the social.' Taken together, CSD's espousal of unpredictability is culturally critical in that it wipes away the false certainties of how, or the lines within, people construct meaning in interaction. It is critical in the sense of counterhegemonic in that it destabilises established systems of difference or regimes of diversity. As we have seen exemplarily in Eckert's eulogy of agency, it appears as though actors build up meaning single-handedly, conjuring up the orders of indexicality of their predilection. The last step towards a CSD consists in adding social critique to cultural critique by bringing in power relations.

The third step consists in CSD engaging with super-diversity's dimension of 'counter-diversity'. The latter includes a range of phenomena which I have situated in dynamics 'from below' - countering, reworking, or simply escaping established identities, categories, standards, registers, styles, etc. Without for that matter having to resort to the concept of class as such, it is essential that any (socially) critical human science retains a general sense of 'above' and 'below', in order to grasp processes of standardisation, enregisterment, named and enumerable languages, styles, genres, etc. In this, Bakhtin and Volosinov provide a firm basis. According to Hall (1996a: 297), 'Volosinov's account counterposed the exercise of cultural power through the imposition of the norm in an attempt to freeze and fix meaning in language to the constant eruption of new meanings, the fluidity of heteroglossia, and the way meaning's inherent instability and heterogeneity dislocated and displaced language's apparently "finished" character.' It is clear that in what White calls Bakhtin's 'critical sociolinguistics of culture' (White 2002: 129), the high and low are thought in an exemplarily monocentric world with the state, the highly coded, the prestigious, and the monoglossia, on the one hand, and the 'folk', the dispersed, the subordinated, and the heteroglossia, on the other hand (Bakhtin 1981: 271; White 2002: 116, 126, 131). For White (2002: 117), this dialogic interaction between 'high' and 'low' forms of language is critical in Bakhtin's model and 'prevents the concept of heteroglossia from degenerating into a mixed bag of sociolinguistic variables.' By taking this on board, CSD should be equipped to inscribe itself in the dynamics of counter-governmentality and counter-diversity described above.

In conclusion, it appears that super-diversity's contribution to contemporary sociolinguistics is important. It is there to remind sociolinguistics of the complex dynamics of diversity both as social and cultural practice and as (hegemonic) discourse and regulation. Moreover, super-diversity may push sociolinguists to go beyond their current limits in an attempt to shape a new moment in the post-colonial history of liberatory and democratising human and social sciences. 


\section{References}

Alim, S. 2009. "Translocal style communities: hip hop youth as cultural theorists of style, language, and globalization." Pragmatics 19(1):103-127.

Andrejevic, M. 2006. "The discipline of watching: detection, risk, and lateral surveillance." Critical Studies in Media Communication 23(5): 391-407.

Appadurai, A. 2001. "Deep democracy: urban governmentality and the horizon of politics." Environment \& Urbanization 13(2):23-43.

Arnaut, K. 2005. “' 'Our Baka brothers obviously do not speak French': siting and scaling physical/ discursive 'movements' in post-colonial Belgium." Language \& Communication 25(3): 217-235.

Bakhtin, M. 1981. The Dialogic Imagination. Austin: Texas University Press.

Barton, D. and K. Tusting, eds. 2006. Beyond Communities of Practice: Language, Power and Social Context. New York: Cambridge University Press.

Bauman, Z. 1991. "A sociological theory of postmodernity." Thesis Eleven 29(1): 33-46.

- 1996. "From pilgrim to tourist - or a short history of identity." In: S. Hall and P. du Gay, eds. Questions of Cultural Identity, London: Sage.

- 2000. Liquid Modernity. Oxford: Blackwell.

Bennett, A. 1999. "Subcultures or neo-tribes? Rethinking the relationship between youth, style and musical taste." Sociology 33(3): 599-617.

Birkett, J. 2006. "(En)countering globalisation: Resistances in the system." In: S. Smith, ed. Globalisation and its Discontents, Cambridge: English Association.

Blommaert, J. 2007. "Sociolinguistics and discourse analysis: orders of indexicality and polycentricity." Journal of Multicultural Discourses 2(2): 115-130.

- 2009. "Ethnography and democracy: Hymes's political theory of language." Text \& Talk 29(3): 257-276.

- 2010. The Sociolinguistics of Globalization. Cambridge: Cambridge University Press.

- 2011. Superdiversiteit. Babylon Werkdocumenten.

- 2012. "Chronicles of complexity: Ethnography, superdiversity, and linguistic landscapes." In: Tilburg Papers in Culture Studies 29. Tilburg: Babylon.

Blommaert, J. and B. Rampton. 2011. "Language and superdiversity: a position paper." Diversities 13(2): 1-21.
Boyne, R. 2000. "Post-Panopticism." Economy and Society 29(2): 285-307.

Cascio, J. 2005. "The rise of the participatory panopticon." http://www.worldchanging.com/archives/002651.html. Worldchanging.

Chauveau, J.-P. and J.-P. Dozon. 1987. "Au coeur des éthnies ivoiriennes . . l'État." In : E. Terray, ed. L'Etat contemporain en Afrique. Paris: L'Harmat$\tan$.

Cheney-Lippold, J. 2011. "A new algorithmic identity: soft biopolitics and the modulation of control." Theory, Culture \& Society 28(6): 164-181.

Corner, J. 1997. "Re-styling the real: British television documentary in the 1990s." Continuum 11(1): 9-22.

Coupland, N. 2010. "Introduction: sociolinguistics in the global era." In: N. Coupland, ed. The Handbook of Language and Globalization. Malden, MA: Wiley-Blackwell.

Deleuze, G.1992. Postscript on the societies of control. October 59:3-7.

Dovey, J. 2000. Freakshow: First person media and factual television. London: Pluto Press.

Eckert, P. 2012. "Three waves of variation study: the emergence of meaning in the study of sociolinguistic variation." Annual Review of Anthropology 41:87-100.

Englund, H. 2004. "Introduction: Recognizing identities, imagining alternatives." In: $\mathrm{H}$. Englund and F. Nyamnjoh, eds. Rights and the politics of recognition in Africa. London: Zed Books.

Fabian, J. 1979. "Rule and process: Thoughts on ethnography as communication." Philosophy of the Social Sciences 9(1):1-26.

- 1999. "Theater and anthropology, theatricality and culture." Journal of Research in African Literatures 30(4):24-31.

Fanshawe, S. and D. Sriskandarajah. 2010. 'You Can't Put Me In A Box': Super-diversity and the end of identity politics in Britain. Institute for Public Policy Research.

Ferguson, J.1994. The anti-politics machine: 'Development', depoliticization, and bureaucratic power in Lesotho. Minneapolis: University of Minnesota Press.

- 1997. "Anthropology and its evil twin: "development" in the constitution of a discipline." In: F. Cooper and R. Packard, eds. International development and the social sciences: essays on the history and politics of knowledge. Berkeley: University of California Press. 
- 2005. "Decomposing modernity: history and hierarchy after development." In: A. Loomba, et al., eds. Postcolonial studies and beyond. Durham: Duke University Press.

Fetveit, A. 1999. "Reality TV in the digital era : a paradox in visual culture?" Media, Culture \& Society 21:787-804.

Foucault, M.1975. Surveiller et punir. Naissance de la prison. Paris: Gallimard.

Fraser, N.2003. "From discipline to flexibilization? Rereading Foucault in the shadow of globalization." Constellations 10(2):160-171.

Grillo, R. D.1997. "Discourses of development anthropological perspectives." In R.D. Grillo and R.L. Stirrat, eds. Discourses of development: The view from anthropology. Oxford: Berg.

Guattari, F. 1990. Vers une ère post-média. Chimères 28 (spring-summer).

Gumperz, J. and J. Cook-Gumperz. 2008. "Studying language, culture, and society: Sociolinguistics or linguistic anthropology?" Journal of Sociolinguistics 12(4):532-545.

Gupta, A. and J. Ferguson. 1992. "Beyond Culture: Space, Identity and the Politics of Difference." Cultural Anthropology 7(1):6-23.

Haggerty, K. 2006. Tear down the walls: on demolishing the panopticon. In: D. Lyon, ed. Theorizing surveillance: The panopticon and beyond. Devon: Willan publishing.

Hall, S.1996a. "For Allan White: Metaphors of transformation." In: D. Morley and K.-H. Chen, eds. On postmodernism and articulation: An Interview with Stuart Hall. London: Routledge.

- 1996b. "Introduction: Who needs identity?" In: S. Hall and P. Du Gay, eds.Questions of Cultural Identity. London: Sage.

- 2000. "Conclusion: The multi-cultural question." In: B. Hesse, ed. Un/settled multiculturalisms: Diasporas, entanglements, 'transruptions'. London: Zed Books.

Hand, M. and B. Sandywell. 2002. "E-topia as cosmopolis or citadel: on the democratizing and dedemocratizing logics of the internet, or, toward a critique of the new technological fetishism." Theory, Culture \& Society 19(1-2):197-225.

Hardt, M. and A. Negri. 2000. Empire. Cambridge, MA: Harvard University Press.

Hirschkop, K.1986. "Bakhtin, discourse and democracy." New Left Review 160(1):92-112.
Howitt, R.1993. "'A world in a grain of sand': towards a reconceptualisation of geographical scale." Australian Geographer 24(1):33-44.

Hymes, D.1972. "The use of anthropology: critical, political, personal." In: D. Hymes, ed. Reinventing anthropology. Ann Arbor: The University of Michigan Press.

- 1975. "Reinventing Anthropology: Response to Kaplan and Donald." American Anthropologist 77(4):869-870.

Jacquemet, M.2005. "Transidiomatic practices: Language and power in the age of globalization." Language \& Communication 25(3):257-277.

Kaplan, M.1995. "Panopticon in Poona: an essay on Foucault and colonialism." Cultural Anthropology 10(1):85-98.

Koskela, H.2004. "Webcams, TV shows and mobile phones: empowering exhibitionism." Surveillance \& Society 2(2/3):199-215.

Latour, B.2010. "An attempt at a 'Compositionist Manifesto'." New Literary History 41:471-490.

Leppänen, S. and S. Peuronen. 2012. "Multilingualism on the Internet." In: M. Martin-Jones, A. Blackledge, and A. Creese, eds. Handbook of Multilingualism. London: Routledge.

Levitt, P. and N. Glick Schiller. 2004. "Transnational perspectives on migration: conceptualizing simultaneity." International Migration Review 38(3):1002-1039.

Maguire, M. 2009. "The birth of biometric security." Anthropology Today 25(2):9-14.

Maher, J. C. 2005. "Metroethnicity, language, and the principle of Cool." International Journal of the Sociology of Language 2005(175-176):83102.

- 2010. "Metroethnicities and metrolanguages." In: N. Coupland, ed. The Handbook of Language and Globalization. Wiley-Blackwell.

Makoni, S. and A. Pennycook. 2007. "Disinventing and reconstituting languages." In: Disinventing and reconstituting languages. Clevedon: Multilingual Matters.

Mamdani, M.1996. Citizen and subject: contemporary Africa and the legacy of late colonialism. Kampala, Cape Town, London: Fountain Publishers, David Philip, James Currey.

Marston, S. A., J.P. Jones, and K. Woodward. 2005. "Human geography without scale." Transactions of the Institute of British Geographers 30(4):416432. 
Marston, S.2000. "The social construction of scale." Progress in Human Geography 24(2):219-242.

Massey, D. 2001. "Talking of space-time." Transactions of the Institute of British Geographers NS 26:257-261.

Mathiesen, T.1997. "The viewer society: Michel Foucault's 'Panopticon' revisited." Theoretical Criminology 1(2):215-234.

Mbembe, A. 1992. "The banality of power and the aesthetics of vulgarity in the postcolony." Public Culture 4(2):1-30.

- 2010. Sortir de la grande nuit: Essai sur l'Afrique décolonisée. Paris: Editions de la Découverte.

Mbembe, A. and S. Nuttall. 2004. "Writing the world from an African metropolis." Public Culture 16(3):347-372.

Mbembe, A. and J. Roitman. 1997. "Figures of the subject in times of crisis." Public Culture 7:323352.

Mirzoeff, N. 2011. The right to look: a counterhistory of visuality. Durham: Duke University Press.

Moore, A. 2008. "Rethinking scale as a geographical category: from analysis to practice." Progress in Human Geography 32(2):203-225.

Negri, A. 2008. Empire and beyond. Cambridge: Polity Press.

Nielsen, M. 2011. "Inverse governmentality: The paradoxical production of peri-urban planning in Maputo, Mozambique." Critique of Anthropology 31(4):329-358.

Olivier de Sardan, J.-P. 2005. Anthropology and development: understanding contemporary social change. London: Zed Books.

Parkin, D. and K. Arnaut. 2012. Super-diversity, a digest. Göttingen: Max Planck Institute for the Study of Religious and Ethnic Diversity.

Pennycook, A. 2007. Global Englishes and transcultural flows. London: Routledge.

- 2012. Language and mobility: Unexpected places. Bristol: Multilingual Matters.

Rampton, B. 1995.Crossing: Language and ethnicity among adolescents. London: Longman.

- 2006. Language in late modernity: Interaction in an urban school. Cambridge: Cambridge University Press.

- 2013. "From 'youth language' to contemporary urban vernaculars." In: A. Deppermann, ed. Das Deutsch der Migranten. Jahrbuch des Instituts für Deutsche Sprache. Berlin / New York: De Gruyter.

Riley, P. 2007. Language, culture and identity: An ethnolinguistic perspective. London: Continuum.
Ruddick, S.2010. "The politics of affect: Spinoza in the work of Negri and Deleuze." Theory, Culture \& Society 27(4):21-45.

Simone, A.M. 2003. "Reaching the larger world: New forms of social collaboration in Pikine, Senegal." Africa: Journal of the International African Institute 73(2):226-250.

- 2005. "Urban circulation and the everyday politics of African urban youth: the case of Douala, Cameroon." International Journal of Urban and Regional Research 29(3):516-532.

- 2010. "On intersections, anticipations, and provisional publics: remaking district life in Jakarta." Urban Geography 31(3):285-308.

Swyngedouw, E.1997. "Excluding the other: the production of scale and scaled politics." In: R. Lee and J. Wills, eds. Geographies of economies. London: Arnold.

Valentine, G. 2008. "Living with differences: refections on geographies of encounter." Progress in Human Geography 32(3):323-337.

Valéry, P. 1931. Regards sur le monde actuel. Paris: Librairie Stock, Delamain et Boutelleau.

Van Dijk, R.2011. "Cities and the social construction of hot spots: Rescaling, Ghanaian migrants, and the fragmentation of urban spaces." In: N. Glick Schiller and A. Çağlar, eds. Locating migration: Rescaling cities and migrants. Cornell University Press.

Vertovec, S.2006. "The emergence of super-diversity in Britain."In: Research on immigration and integration in the metropolis, Vol. No. 06-14: Working Paper Series: Vancouver Centre of Excellence.

- 2007a. New complexities of cohesion in Britain: super-diversity, transnationalism and civil-integration. Commission on Integration and Cohesion.

- 2007b. "Super-diversity and its implications." Ethnic and Racial Studies 30(6):1024-1054.

- 2010. "Towards post-multiculturalism? Changing communities, conditions and contexts of diversity." International Social Science Journal 61(199):83-95.

- 2012. "Diversity' and the social imaginary." European Journal of Sociology 53(3):287-312.

Vigouroux, C. B. 2008. "From Africa to Africa: Migration, globalization and language vitality." In: C.B. Vigouroux and S.S. Mufwene, eds. Globalization and language vitality : perspectives from Africa. London; New York: Continuum. 
Virno, P. 2004. A grammar of the multitude: For an analysis of contemporary forms of life. Los Angeles: Semiotext(e).

Virno, P. and M. Hardt, eds.1996. Radical thought in Italy: A potential politics. Minneapolis: University of Minnesota Press.

Weibel, P. 2002. "Pleasure and the panoptic principle." In: T. Levin, U. Frohne, and P. Weibel, eds. Ctrl [Space] rhetorics of surveillance from Bentham to Big Brother. Cambridge (Mass.) \& London: MIT Press.

Wenger, E. 2000. "Communities of practice and social learning systems." Organization 7(2):225246.
Whitaker, R. 1999. The end of privacy: How total surveillance is becoming reality. New York: The New Press.

White, A. 2002. "Bakhtin, sociolinguistics and deconstruction." In: Mikhail Bakhtin (4th edition). M. Gardiner, ed. Pp. 114-132, Vol. III. London: Sage.

Wolf, E. R.1964. Anthropology. New York: Norton. Woolard, K. A. 1998. "Simultaneity and bivalency as strategies in bilingualism." Journal of Linguistic Anthropology 8(1):3-29.

\section{Note on the Author}

Karel ARNAUT is a Research Fellow at the Max Planck Institute for the Study of Religious and Ethnic Diversity (Göttingen) where he conducts research on aspects of sociolinguistic superdiversity in city-based transactions between Africa and Europe. The main focus of his work is on the transnationalisation of public spaces as well as postcolonial dynamics in the area of diasporic identity-formation and activism in urban contexts in Europe and Africa. 